\title{
Infection and Erosion Rates in Trials of a Cranially Implanted Neurostimulator Do Not Increase with Subsequent Neurostimulator Placements
}

\author{
Peter B. Weber ${ }^{a}$ Ritu Kapur ${ }^{d}$ Ryder P. Gwinn ${ }^{b}$ Richard S. Zimmerman ${ }^{c}$ \\ Tracy A. Courtney ${ }^{d}$ Martha J. Morrell ${ }^{d, e}$ \\ ${ }^{a}$ California Pacific Medical Center, San Francisco, CA, ${ }^{b}$ Swedish Neuroscience Institute, Seattle, WA, \\ 'Department of Neurosurgery, Mayo Clinic Hospital, Phoenix, AZ, d NeuroPace Inc., Mountain View, CA, and \\ e Stanford University, Stanford, CA, USA
}

\section{Keywords}

Complications · Epilepsy · Stimulation · Surgery

\begin{abstract}
Background/Aims: The RNS ${ }^{\circledR}$ System utilizes a cranially implanted neurostimulator attached to leads placed at the seizure focus to provide brain responsive stimulation for the treatment of medically intractable partial onset epilepsy. Infection and erosion rates related to the cranial implant site were assessed overall and by neurostimulator procedure to determine whether rates increased with additional procedures. Methods: Infection and erosion rates were calculated as (1) chance per neurostimulator procedure, (2) incidence per patient implant year, and (3) rates for initial and each subsequent neurostimulator implant (generalized estimating equation). Results: In 256 patients followed for an average of 7 years, the infection rate was $3.7 \%$ per neurostimulator procedure $(n=31 / 840)$, and the rate of erosions was $0.8 \%$ per neurostimulator procedure $(n=7 / 840)$. Rates did not increase with subsequent neurostimulator procedures ( $p=$ 0.66 , infection; $p=0.70$, erosion). A prior infection or erosion at the implant site did not significantly increase the risk at a later procedure ( $p \geq 0.05$ for all combinations). Conclusion: These data indicate that the risk for infection compares fa-
\end{abstract}

\begin{tabular}{ll}
\hline KARGER & $\begin{array}{l}\text { ( } 2017 \text { The Author(s) } \\
\text { Published by S. Karger AG, Basel }\end{array}$ \\
$\begin{array}{l}\text { E-Mail karger@karger.com } \\
\text { www.karger.com/sfn }\end{array}$ & $\begin{array}{l}\text { This article is licensed under the Creative Commons Attribution 4.0 } \\
\text { International License (CC BY) (http://www.karger.com/Services/ } \\
\text { OpenAccessLicense). Usage, derivative works and distribution are } \\
\text { permitted provided that proper credit is given to the author and the } \\
\text { original publisher. }\end{array}$
\end{tabular}

vorably to other neurostimulation devices and suggest that rates of infection and erosion do not increase with subsequent neurostimulator replacements.

(C) 2017 The Author(s)

Published by S. Karger AG, Basel

\section{Introduction}

Brain responsive stimulation using the RNS ${ }^{\circledR}$ System is approved in the USA as an adjunctive treatment for medically intractable partial onset seizures in adults. Unlike currently available open loop deep brain stimulation systems that utilize a pectoral implant for the pulse generator, the RNS System neurostimulator is cranially implanted. Experience from prospective clinical trials provides data regarding the risk of infection and erosion related to the cranial implant approach.

\section{Methods}

The RNS System provides targeted responsive neurostimulation via a cranially implanted programmable neurostimulator connected to 1 or 2 depth and/or subdural cortical strip leads placed at 1 or 2 previously identified seizure foci [1]. Each lead contains 4 electrode contacts, through which the neurostimulator continu-

Tracy A. Courtney, BS, CCRP

NeuroPace Inc.

455 N. Bernardo Avenue

Mountain View, CA 94043 (USA)

E-Mail tcourtney@neuropace.com 
ously senses electrocorticographic activity. The device is programmed by the physician to detect specific patterns in the electrocorticogram and to deliver brief stimulation pulses in response. Recording and stimulation occur on the same electrodes. The physician adjusts detection and stimulation parameters for each patient as needed for seizure reduction. The typical patient receives brief bursts of high-frequency stimulation with a total cumulative stimulation time of less than 6 min a day [2].

Patients were implanted with the RNS Neurostimulator and NeuroPace Leads while enrolled in either a primarily open-label safety study or in a randomized double-blind controlled trial [3]. Two years after the neurostimulator implant, patients were able to transition into a 7-year long-term open-label follow-up study. The studies are registered on www.clinicaltrials.gov (NCT00079781, NCT00264810, NCT00572195). All patients gave informed written consent.

Data were collected on infections and erosions associated with any neurostimulator procedure (i.e., initial implant, replacement, or explant). Any mention of an infection or erosion on a case report form was examined, regardless of culture or use of antibiotics. Patients who had a neurostimulator explanted without a replacement were followed for 6 weeks after the surgery and contributed data to the analysis. Included in the analysis were all serious adverse events (SAEs) related to infection or erosion that were identified by the investigator as device related or of uncertain device relation, and were not due to seizure-related injuries. An SAE was defined as one requiring hospitalization or a surgical procedure. An independent data-monitoring committee reviewed all adverse events.

The relationship between infection or erosion rate and procedure number (first to fourth) was assessed using a logistic generalized estimating equation (GEE) method. GEE is an extension of generalized linear modeling that appropriately accounts for the correlation of multiple measures from the same subjects [4]. The model used logistic regression to fit a linear model with procedure number (1-4) as a linear independent variable to predict infection or erosion probability. An additional constant cohort analysis was performed, in which only patients with at least 4 procedures were included in the analysis. Paired differences across subsequent procedure numbers were compared using the McNemar test.

\section{Results}

Patients treated with the RNS Neurostimulator and NeuroPace Leads $(n=256)$ were followed for an average of 6.9 years (10 days to 11 years). Twenty-eight patients had a total of 31 events related to infection over 1,715 patient implant years ( 0.018 per implant year). The rate of SAEs related to an incision or implant site infection was $3.7 \%$ per neurostimulator procedure $(n=31 / 840)$.

Fourteen of the 31 infections (45\%) were reported to have occurred within the first postoperative month; 3 of these were asymptomatic infections discovered during a routine neurostimulator replacement procedure. The remaining 17 infection SAEs had reported onsets that ranged from 35 days to 3.5 years after the neurostimulator procedure.

All patients with infections were treated with antibiotics, and debridement was performed in $61 \%$ of cases. Twenty-one percent of patients (6/28) continued to receive responsive therapy with no change in the neurostimulator or leads. Another 21\% (6/28) had the neurostimulator replaced with no change to the leads, and continued to receive responsive therapy thereafter. The remaining patients $(57 \%, 16 / 28)$ had the neurostimulator explanted, and 13 had leads explanted as well. Two of these patients were subsequently reimplanted with the neurostimulator and leads. None of the 3 patients with leads remaining reported any instance of meningitis or needed a subsequent surgery to remove remaining leads (duration of follow-up: 59, 461, and 1,336 days after device removal).

Infections in all but 1 of the 28 patients involved only soft tissue; there were no instances of meningitis. One patient developed osteomyelitis after a single hospitalization that included explantation of the neurostimulator and leads followed by 7 days of subdural grid mapping, a frontal lobe resection, and reimplantation of the RNS Neurostimulator and leads.

There were 5 patients with a total of 7 SAEs related to erosion over the 1,715 patient implant years (0.004 erosions per implant year). Two of the 5 patients had the neurostimulator implanted with the inner table of the skull intact, so that the neurostimulator protruded above the skull. The overall rate of erosion was $0.8 \%$ per neurostimulator procedure. All patients were treated with antibiotics. One patient continued to receive responsive therapy with no change to the neurostimulator or leads. Four patients had the neurostimulator explanted, and 2 had leads explanted as well. Of these, 1 patient had the neurostimulator and leads replaced at a later date. For the 2 patients with abandoned leads, there were no reports of meningitis or subsequent surgery to remove the leads (duration of follow-up: 250 and 754 days after device removal). One of these patients with a history of prior intracranial monitoring had a cranioplasty 20 months after the device had been explanted.

No cultures were provided for 4 of the events related to infection or erosion, and 1 culture was negative. Other cultures were as follows (cultures for a single infection or erosion event could be positive for more than 1 type of bacterium): gram-positive cocci - Staphylococcus (S. aureus 11 , S. epidermis 1 , other 9), not further specified (1); gram-positive rods - Propionibacterium (7), not further specified (1); gram-negative rods - Enterobacter (3), 
Table 1. Number of patients reporting infections or erosions after each neurostimulator procedure

\begin{tabular}{llllll}
\hline $\begin{array}{l}\text { Proce- } \\
\text { dure }\end{array}$ & $\begin{array}{l}\text { Total } \\
\text { of patients, } \\
n\end{array}$ & $\begin{array}{l}\text { Patients } \\
\text { reporting } \\
\text { infection }^{1}, n\end{array}$ & $\begin{array}{l}\text { Infection } \\
\text { events, } n\end{array}$ & $\begin{array}{l}\text { Patients } \\
\text { reporting } \\
\text { erosion }^{1}, n\end{array}$ & $\begin{array}{l}\text { Erosion } \\
\text { events, } n\end{array}$ \\
\hline 1st & 265 & 6 & 8 & 2 & 2 \\
2nd & 236 & 8 & 8 & 1 & 1 \\
3rd & 188 & 8 & 8 & 0 & 0 \\
4th & 100 & 2 & 2 & 2 & 2 \\
5th & 37 & 2 & 2 & 0 & 0 \\
6th & 14 & 2 & 2 & 0 & 0 \\
7th & 7 & 1 & 1 & 2 & 2 \\
8th & 2 & 0 & 0 & 0 & 0 \\
\hline
\end{tabular}

All serious adverse events related to infection or erosion were identified by the investigator as device related or of uncertain device relation, and were not due to seizure-related injuries. Data as of November 1st, 2015.

${ }^{1}$ This column represents the number of unique patients who had an infection or erosion in the time period between the $n$th and the $n+1$ st procedure. The sum of patients in this column does not reflect the number of unique patients who ever had an infection/ erosion, because any patient having an adverse event in more than one $n$th procedure bin would be represented multiple times. ${ }^{{ }^{\circ}} 2017$ NeuroPace Inc.

Pseudomonas (3), Serratia (3), Escherichia coli (1), not further specified (1).

To assess whether the risk of infection or erosion changed with subsequent neurostimulator procedures, the rate of infection or erosion by the $n$th procedure was analyzed through 4 procedures (Fig. 1); there were not sufficient numbers of patients with more than 4 procedures to extend the analysis beyond this point (Table 1). Note that this analysis includes data from the first-generation neurostimulator, which had a median battery longevity of 2.2 years [5], as well as a later-generation neurostimulator with an estimated battery longevity of 3.9 years [6]. Development of a next-generation device with substantially increased battery life has been completed [NeuroPace Inc., pers. commun.].

Rates of infection did not statistically significantly increase or decrease with more procedures $(p=0.66)$ nor did the rates of erosion ( $p=0.70$, GEE, Fig. 1$)$. A constant cohort analysis in the 100 patients who had at least 4 neurostimulator procedures indicated that an infection or erosion at a prior procedure did not significantly increase the risk of having an infection or erosion at a later procedure ( $p \geq 0.05$ for all combinations, McNemar exact test).

Infection and Erosion Rates in Trials of a Cranially Implanted Neurostimulator

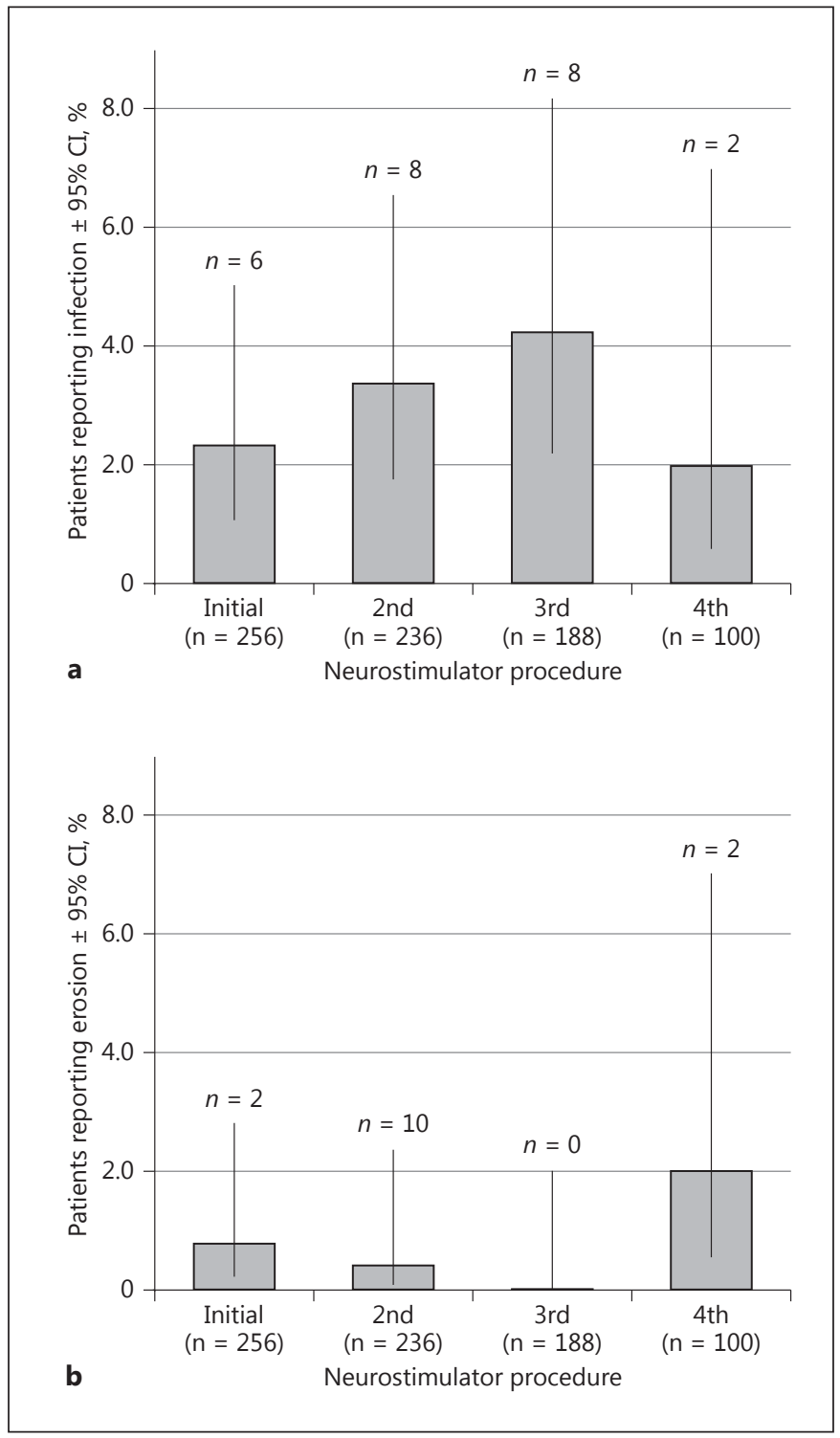

Fig. 1. Percentage of patients reporting an infection (a) or erosion (b) after a neurostimulator procedure. Rates of infection and erosion were analyzed for all patients who had at least 4 procedures; there were not sufficient numbers of patients with more than 4 procedures to extend the analysis further. Neither the percentage of patients with infections ( $p=0.66$, GEE) nor that of patients with erosions $(p=0.70, \mathrm{GEE})$ increased over time. ${ }^{\circledR} 2017$ NeuroPace Inc.

\section{Discussion}

The RNS System is demonstrated to be safe and effective as an adjunctive treatment for medically intractable partial onset seizures in adults based on the results of clinical trials conducted in 256 patients across 32 comprehensive epilepsy centers in the USA $[3,7]$. These data indicate

Stereotact Funct Neurosurg 2017;95:325-329 DOI: $10.1159 / 000479288$ 
that the risk of infection or erosion related to the cranially implanted neurostimulator is not higher than is expected with comparable epilepsy procedures in which a stimulating device is implanted pectorally, and that there is not an increased risk with additional neurostimulator replacement procedures.

The advantages of a cranially implanted neurostimulator are both technical (there is an excellent signal-tonoise ratio, which is important to a responsive system) and cosmetic (the neurostimulator is not apparent to the patient and others). Anticipated advantages over a pectoral implant are a lower risk for lead or device migration [8]. Considerable prospective data from clinical trials of the RNS System indicate that the risk of infection or erosion with the cranial implant compares favorably with other neurostimulation systems that utilize a pectorally implanted pulse generator, such as vagal nerve stimulation [1] and deep brain stimulation for Parkinson disease [9] or epilepsy [8], and that this risk does not increase with subsequent routine neurostimulator replacements. These data support the hypothesis that a cranially implanted stimulator may offer several technical advantages over one placed pectorally without increasing the risk of infection or erosion.

\section{Acknowledgments}

We would like to thank the patients and families, for participating in the RNS System trials.

We also thank the following: California Pacific Medical Center: David King-Stephens, MD, and Kenneth D. Laxer, MD; Dartmouth-Hitchcock Medical Center: Joshua P. Aronson, MD, Krzysztof A. Bujarski, MD, Ann-Christine Duhaime, MD, Gregory L. Holmes, MD, Barbara C. Jobst, MD, Erik J. Kobylarz, MD, PhD, Richard P. Morse, MD, David W. Roberts, MD, and Vijay M. Thadani, MD, PhD; Emory University School of Medicine: Charles M. Epstein, MD, Rebecca Fasano, MD, Raymond E. Faught, Jr., MD, Robert E. Gross, MD, PhD, Suzette M. LaRoche, MD, Kimford J. Meador, MD, Page B. Pennell, MD, and Andres A. Rodriguez Ruiz, $\mathrm{MD}$, and Sandra L. Helmers, MD, MPH, in memoriam; George Washington University School of Medicine and Health Sciences: Anthony J. Caputy, MD, James W. Leiphart, MD, Samuel J. Potolicchio, Jr., MD, and Donald C. Shields, MD; Henry Ford Hospital: Ellen L. Air, MD, PhD, Gregory L. Barkley, MD, David E. Burdette, MD, Konstantin V. Elisevich, MD, PhD, Shailaja Gaddam, MD, Andrea Sneider Hakimi, DO, Madhuri L. Koganti, MD, Amit Ray, MD, Jason M. Schwalb, MD, Brien J. Smith, MD, Marianna V. Spanaki-Varelas, MD, $\mathrm{PhD}$, and Vibhangini S. Wasade, MD; Johns Hopkins University School of Medicine: William S. Anderson, $\mathrm{MD}, \mathrm{PhD}$, Gregory K. Bergey, MD, George I. Jallo, MD, Eric H. Kossoff, MD, Frederick A. Lenz, MD, PhD, and Eva Katharina Ritzl, MD; Keck School of Medicine of USC: Rami G. Apelian, MD, MPH, Vidya P. Hawkins, DO, Christianne Heck, MD, Neda Heidari, MD, Laura A. Kalayjian, MD, Reed L. Levine, MD, Lynn

C. Liu, MD, Andrew D. Ly, MD, Johnson L. Moon, MD, Jason S. Muir, MD, George Nune, MD, Ron A. Shatzmiller, MD, MS, Parastou Shilian, MD, and Steven N. Sykes, MD; Mayo Clinic - Scottsdale, AZ: Joseph F. Drazkowski, MD, Katherine H. Noe, MD, PhD, Naresh P. Patel, MD, and Joseph I. Sirven, MD; Medical College of Georgia at Augusta University: Cole A. Giller, MD, PhD, MBA, Ki Hyeong Lee, MD, MS, Mark R. Lee, MD, PhD, Anthony M. Murro, MD, Yong D. Park, MD, Jeffrey M. Politsky, MD, MS, Joseph R. Smith, MD, Suzanne M. Strickland, MD, and Jeffrey A. Switzer, DO, MD; Nicklaus Children's Hospital: Sanjiv Bhatia, MD, Michael S. Duchowny, MD, Prasanna Jayakar, MD, PhD, Ian Miller, MD, Glen Morrison, MD, John Ragheb, MD, and Trevor J. Resnick, MD; Oregon Health and Science University: James J. Cereghino, MD, MS, Lia Ernst, MD, Felicia A. Ferguson, MD, Mary M. Ransom, MD, Martin C. Salinsky, MD, MS, William Brewster Smith, MD, and David C. Spencer, MD; Rush University Medical Center: Donna C. Bergen, MD, Richard W. Byrne, MD, Marvin A. Rossi, $\mathrm{MD}, \mathrm{PhD}$, and Michael C. Smith, MD; Swedish Medical Center: Lisa M. Caylor, MD, Michael J. Doherty, MD, John D. Morgan, MD, and David G. Vossler, MD; The Cleveland Clinic Foundation: Andreas V. Alexopoulos, MD, MPH, William E. Bingaman, MD, Balu Krishnan, PhD, Imad Michel Najm, MD and Dileep R. Nair, MD; Thomas Jefferson University Hospital: James J. Evans, MD, Scott E. Mintzer, MD, Maromi Nei, MD, Ashwini D. Sharan, MD, Christopher Skidmore, MD, Michael R. Sperling, MD, and Andro Zangaladze, MD, PhD; University of Florida Medical Center: Jeffrey M. Chung, MD, Jean E. Cibula, MD, Stephan Eisenschenk, MD, George A. Ghacibeh, MD, Kimford J. Meador, MD, and Steven N. Roper, MD; University of Texas Southwestern Medical Center: Mark A. Agostini, MD, Sachin Dave, MD, Ramon Diaz-Arrastia, MD, PhD, Puneet K. Gupta, MD, MSE, Ryan Hays, MD, Bradley Lega, MD, Christopher J. Madden, MD, Pradeep N. Modur, MD, MS, Paul C. Van Ness, MD, and Louis Anthony Whitworth, MD; University of Wisconsin Hospital and Clinics: Azam S. Ahmed, MD, Mustafa K. Baskaya, MD, Brad R. Beinlich, MD, John C. Jones, MD, Lincoln F. Ramirez, MD, PhD, Paul Rutecki, MD, Raj D. Sheth, MD, Karl A. Sillay, MD, and Evelyn C. Tunnell, MD; Via Christi Epilepsy Center: Aamr A. Herekar, MD, Kore K. Liow, MD, Andrew D. Massey, MD, and Nazih Moufarrij, MD.

References
328
Stereotact Funct Neurosurg 2017;95:325-329 DOI: $10.1159 / 000479288$
1 Kahlow H, Olivecrona M: Complications of vagal nerve stimulation for drug-resistant epilepsy: a single center longitudinal study of 143 patients. Seizure 2013;22:827-833.

2 Heck CN, King-Stephens D, Massey AD, Nair DR, Jobst BC, Barkley GL, Salanova V, Cole AJ, Smith MC, Gwinn RP, Skidmore C, Van Ness PC, Bergey GK, Park YD, Miller I, Geller E, Rutecki PA, Zimmerman R, Spencer DC, Goldman A, Edwards JC, Leiphart JW, Wharen RE, Fessler J, Fountain NB, Worrell GA, Gross RE, Eisenschenk S, Duckrow RB, Hirsch LJ, Bazil C, O'Donovan CA, Sun FT, Courtney TA, Seale CG, Morrell MJ: Twoyear seizure reduction in adults with medically intractable partial onset epilepsy treated with responsive neurostimulation: final results of the RNS System pivotal trial. Epilepsia 2014;55:432-441.
Weber/Kapur/Gwinn/Zimmerman/ Courtney/Morrell 
3 Morrell MJ; RNS System in Epilepsy Study Group: Responsive cortical stimulation for the treatment of medically intractable partial epilepsy. Neurology 2011;77:1295-1304.

4 Zeger SL, Liang KY: Longitudinal data analysis for discrete and continuous outcomes. Biometrics 1986;42:121-130.

5 NeuroPace Inc: RNS System clinical summary, RNS 300 model, DN 1014918, Rev 2. 2014. http://www.neuropace.com/manuals/ClinicalSummary.pdf.

6 NeuroPace Inc: RNS System user manual, RNS-300M model, DN 1015882. 2016. http:// www.neuropace.com/manuals/RNS_System_User_Manual.pdf.

7 Bergey GK, Morrell MJ, Mizrahi EM, Goldman A, King-Stephens D, Nair D, Srinivasan
S, Jobst B, Gross RE, Shields DC, Barkley G, Salanova V, Olejniczak P, Cole A, Cash SS, Noe K, Wharen R, Worrell G, Murro AM, Edwards J, Duchowny M, Spencer D, Smith M, Geller E, Gwinn R, Skidmore C, Eisenschenk S, Berg M, Heck C, Van Ness P, Fountain N, Rutecki P, Massey A, O'Donovan C, Labar D, Duckrow RB, Hirsch LJ, Courtney T, Sun FT, Seale CG: Long-term treatment with responsive brain stimulation in adults with refractory partial seizures. Neurology 2015;84:810817.

8 Salanova V, Witt T, Worth R, Henry TR, Gross RE, Nazzaro JM, Labar D, Sperling MR, Sharan A, Sandok E, Handforth A, Stern JM, Chung S, Henderson JM, French J, Baltuch G, Rosenfeld WE, Garcia P, Bar- baro NM, Fountain NB, Elias WJ, Goodman RR, Pollard JR, Tröster AI, Irwin CP, Lambrecht K, Graves N, Fisher R; SANTE Study Group: Long-term efficacy and safety of thalamic stimulation for drug-resistant partial epilepsy. Neurology 2015;84:10171025.

9 Weaver FM, Follett K, Stern M, Hur K, Harris C, Marks WJ Jr, Rothlind J, Sagher O, Reda D, Moy CS, Pahwa R, Burchiel K, Hogarth P, Lai EC, Duda JE, Holloway K, Samii A, Horn S, Bronstein J, Stoner G, Heemskerk J, Huang GD; CSP 468 Study Group: Bilateral deep brain stimulation vs best medical therapy for patients with advanced Parkinson disease: a randomized controlled trial. JAMA 2009;301: 63-73.
Infection and Erosion Rates in Trials of a Cranially Implanted Neurostimulator
Stereotact Funct Neurosurg 2017;95:325-329 DOI: 10.1159/000479288 